\title{
The Endocannabinoid 2-Arachidonoyl-Glycerol Controls Odor Sensitivity in Larvae of Xenopus laevis
}

\author{
Esther Breunig, ${ }^{1,2}$ Ivan Manzini, ${ }^{1,3}$ Fabiana Piscitelli, ${ }_{4}^{4}$ Benjamin Gutermann, ${ }^{1}$ Vincenzo Di Marzo, ${ }^{4}$ Detlev Schild, ${ }^{1,2,3}$ \\ and Dirk Czesnik ${ }^{1}$ \\ ${ }^{1}$ Department of Neurophysiology and Cellular Biophysics, University of Göttingen, ${ }^{2}$ Deutsche Forschungsgemeinschaft Cluster of Excellence 171, and \\ ${ }^{3}$ Deutsche Forschungsgemeinschaft Research Center for Molecular Physiology of the Brain, 37073 Göttingen, Germany, and ${ }^{4}$ Endocannabinoid Research \\ Group, Institute of Biomolecular Chemistry, Consiglio Nazionale delle Ricerche, 80078 Pozzuoli, Naples, Italy
}

Cannabinoids modulate the activity of many neuronal cells, among them sensory neurons in the olfactory epithelium. Here we show that the endocannabinoid 2-arachidonoyl-glycerol (2-AG) is synthesized in both olfactory receptor neurons and glia-like sustentacular cells in larval Xenopus laevis. Its production in the latter depends on the hunger state of the animal. The essential effect of 2-AG in olfactory receptor neurons is the control of odorant detection thresholds via cannabinoid $\mathrm{CB}_{1}$ receptor activation. Hunger renders olfactory neurons more sensitive. Endocannabinoid modulation in the nose may therefore substantially influence food-seeking behavior.

\section{Introduction}

The search for food is known to be guided by the sense of smell (Duclaux et al., 1973; Rolls, 2005). Most animals, including humans, use olfactory information to appreciate food palatability and initiate food intake (Rolls, 2005). Furthermore, the impairment of olfactory signaling may affect the control of eating behavior (Fedoroff et al., 1995; Kopala et al., 1995). It has been suggested that the feeding state modulates the olfactory sensitivity at several stages of the olfactory pathway. However, the underlying signaling systems and the cellular effects responsible for the functional interaction between olfaction and food intake are as yet poorly understood (Apelbaum et al., 2005; Getchell et al., 2006; Aimé et al., 2007; Julliard et al., 2007).

The endocannabinoid system may play an eminent role in this regard. Olfactory centers of various species have been shown to express the endocannabinoid system (Tsou et al., 1998; Egertová and Elphick, 2000; Mackie, 2005; McPartland et al., 2006). Endocannabinoids also act on olfactory receptor neurons (ORNs) in the olfactory epithelium. Blockage of cannabinoid $\mathrm{CB}_{1}$ receptors diminishes and delays responses to food odorants (Czesnik et al., 2007). Furthermore, $\mathrm{CB}_{1}$ receptors in type II taste cells have been shown recently to participate in the enhancement of sweet taste (Yoshida et al., 2010).

The endocannabinoid system is important for energy homeostasis and nutrition (Horvath, 2006; Osei-Hyiaman et al.,

Received Aug. 17, 2009; revised April 9, 2010; accepted April 14, 2010.

This work was supported by grants from the Research Program, Faculty of Medicine, Georg-August-Universität Göttingen (D.C.) and Deutsche Forschungsgemeinschaft Research Center Molecular Physiology of the Brain (D.S. I.M.) and the Cluster of Excellence 171 (E.B., D.S.). We thank the DNA Microarray Facility of the University of Göttingen for providing the laboratory equipment for some of the molecular biological experiments. Furthermore, we thank Gudrun Federkeil for excellent technical help. We also thank Prof. G. Ortar, University of Rome "La Sapienza" for the kind gift of OMDM187 and OMDM188.

Correspondence should be addressed to Dirk Czesnik, Department of Neurophysiology and Cellular Biophysics, University of Göttingen, Humboldtallee 23, 37073 Göttingen, Germany. E-mail: dczesni@gwdg.de.

DOI:10.1523/JNEUROSCI.4030-09.2010

Copyright $\odot 2010$ the authors $\quad 0270-6474 / 10 / 308965-09 \$ 15.00 / 0$
2006; Matias and Di Marzo, 2007). At the central stages of the nervous system, it has been well described that the endocannabinoid system plays a dual role in the regulation of food intake as well as in the homeostatic and nonhomeostatic (or hedonic) energy regulation (Matias et al., 2008). Additionally, selective inverse agonists of $\mathrm{CB}_{1}$ receptors have been developed for weight loss and the treatment of obesity-associated metabolic disorders (Engeli, 2008). It is obvious that the central processes involved in linking olfaction to food intake would hardly stay unaffected by an increased or decreased sensitivity of ORNs.

Here, we report that the endocannabinoid 2-arachidonoylglycerol (2-AG) is synthesized in the olfactory epithelium, in both ORNs and sustentacular cells (SCs), and that 2-AG synthesis depends on the hunger state of an animal. We show that detection thresholds of individual ORNs to food odorants are decreased under endocannabinoid modulation, which emphasizes the orexigenic role of 2-AG in the olfactory epithelium.

\section{Materials and Methods}

Slice preparation for $\left[\mathrm{Ca}^{2+}\right]_{i}$ imaging and patch clamping

Tadpoles of Xenopus laevis of both genders (stages 51-54) (Nieuwkoop and Faber, 1994) were picked randomly, chilled in a mixture of ice and water, and decapitated, as approved by the Göttingen University Committee for Ethics in Animal Experimentation. A block of tissue containing the olfactory epithelium, the olfactory nerves, and the brain was cut out and kept in bath solution (see below). The tissue was then glued onto the stage of a vibroslicer (VT 1000S; Leica) and cut horizontally into 130to $150-\mu \mathrm{m}$-thick slices.

For patch clamping, the slices were placed under a grid in a recording chamber and viewed using Nomarski optics (Axioskop 2; Carl Zeiss).

For imaging $\left[\mathrm{Ca}^{2+}\right]_{\mathrm{i}}$, the tissue slices were incubated in $200 \mu \mathrm{l}$ of a bath solution (see below) containing $50 \mu \mathrm{M}$ fluo-4 AM (Invitrogen) and $50 \mu \mathrm{M}$ MK571 (3-[\{3-[(E)-2-(7-chloro-quinolin-2-yl)-vinyl]-phenyl\}(2-diethylcarbamoyl-ethylsulfanyl)-methylsulfanyl]-propionic acid) (Alexis Biochemicals). Fluo-4 AM was dissolved in dimethylsulfoxide (DMSO) (Sigma) and Pluronic F-127 (Invitrogen). The final concentrations of DMSO and Pluronic F-127 did not exceed 0.5 and $0.1 \%$, respec- 
tively. To avoid multidrug resistance transporter-mediated destaining of the slices, MK571 [5-(3-(2-(7-chloroquinolin-2-yl)ethenyl)phenyl)-8dimethylcarbamyl-4,6-dithiaoctanoic acid], a specific inhibitor of the multidrug resistance-associated proteins was added to the incubation solution (Manzini and Schild, 2003a). After incubation at room temperature for $35 \mathrm{~min}$, the tissue slices were put under a grid in a recording chamber and placed on the microscope stage of an Axiovert 100M (Carl Zeiss) to which a laser-scanning unit (LSM 510; Carl Zeiss) was attached.

Before starting the $\left[\mathrm{Ca}^{2+}\right]_{\mathrm{i}}$ imaging or patch-clamp experiments, the slices were rinsed with bath solution for at least $5 \mathrm{~min}$.

\section{Solution and stimulus application}

The composition of the bath solution was as follows (in $\mathrm{mM}$ ): $98 \mathrm{NaCl}, 2$ $\mathrm{KCl}, 1 \mathrm{CaCl}_{2}, 2 \mathrm{MgCl}_{2}, 5$ glucose, 5 sodium pyruvate, and $10 \mathrm{HEPES}$. The pipette solution contained the following (in $\mathrm{mM}$ ): $2 \mathrm{NaCl}, 11 \mathrm{KCl}, 2$ $\mathrm{MgSO}_{4}, 80 \mathrm{~K}$-gluconat, $10 \mathrm{HEPES}, 0.2$ EGTA, $1 \mathrm{Na}_{2} \mathrm{ATP}$, and 0.1 $\mathrm{Na}_{2} \mathrm{GTP}, \mathrm{pH}$ was adjusted to 7.8 . The osmolarities of the solutions were $230 \mathrm{mOsm} / \mathrm{L}$ for bath solution and $190 \mathrm{mOsm} / \mathrm{L}$ for the pipette solution. As odorants, we used the mixture of 19 aa as in our previous work (Manzini et al., 2002; Manzini and Schild, 2003b) or single amino acids (arginine, lysine, and methionine). Amino acids are well known food odorants in aquatic animals (Sorensen and Caprio, 1998; Valentincic et al., 1999; Nikonov et al., 2005). The amino acids were dissolved in bath solution (stocks of $10 \mathrm{~mm}$ ) and used at a final concentration of $0.2 \mu \mathrm{M}$ to $2 \mathrm{~mm}$ in the experiments. Stimulus solutions were prepared immediately before use by dissolving the respective stock solution in bath solution. The bath solution was applied by gravity feed from a storage syringe through a funnel drug applicator to the recording chamber. Stimuli were pipetted directly into the funnel without stopping the flow. Outflow was through a syringe needle placed close to the olfactory epithelium. The time course of stimulus arrival at the olfactory epithelium was simulated by applying the fluorescent dye avidin AlexaFluor-488 as a dummy stimulus and by measuring the fluorescence after avidin AlexaFluor- 488 application to the funnel. The delay of stimulus arrival caused by the syringe, i.e., from pipetting into the funnel to the resulting concentration increase in the olfactory epithelium, was $\sim 2 \mathrm{~s}$. The minimum interstimulus interval between odorant applications was at least $2 \mathrm{~min}$. All of the chemicals were purchased from Sigma, if not indicated otherwise. The $\mathrm{CB}_{1}$ receptor drugs AM281 [1-(2,4-dichlorophenyl)-5- (4-iodophenyl) -4-methyl- $N$-4-morpholinyl-1 H-pyrazole-3-carboxamide] and HU210 [(6aR)-trans-3-(1,1' -dimethylheptyl)-6a,7,10,10a-tetrahydro-1-hydroxy6,6-dimethyl-6H-dibenzo[b,d]pyran-9-methanol] and the DAG lipase blocker RHC80267 (O, $O^{\prime}$-[1,6-hexanediylbis(iminocarbonyl)] dioxime cyclohexanone) (Tocris Bioscience) (stocks of 10 or $20 \mathrm{~mm}, 100 \%$ DMSO), orlistat ( $N$-formyl-L-leucine-(1S)-1[[(2S,3S)-3-hexyl-4-oxo-2-oxetanyl] methyl]dodecyl ester) (Tocris Bioscience) (stocks of $25 \mathrm{~mm}, 100 \%$ DMSO), OMDM-187 ( $N$-formyl-L-valine-(1S)-1-[[(2S,3S)-3-hexyl-4-oxo-2-oxetanyl] methyl] dodecyl ester) (compound 13 in the study by Ortar et al., 2008) (stocks of $1 \mathrm{~mm}, 100 \%$ DMSO), and OMDM-188 (compound 15 in the study by Ortar et al., 2008) (stocks of $1 \mathrm{mM}, 100 \%$ DMSO, OMDM-187, and OMDM-188 ( $N$-formyl-L-isoleucine-(1S)-1-[[(2S,3S)-3-hexyl-4-oxo-2-oxetanyl]methyl] dodecyl ester) were kind gifts from Prof. G. Ortar (University of Rome "La Sapienza," Rome, Italy) were dissolved in bath solution and used at final concentrations as indicated in Results or the figure legends.

\section{$\left[\mathrm{Ca}^{2+}\right]_{i}$ imaging of odorant-induced responses}

$\left[\mathrm{Ca}^{2+}\right]_{\mathrm{i}}$ was monitored using a laser-scanning confocal microscope (LSM 510; Carl Zeiss). The confocal pinhole was set to $\sim 120 \mu \mathrm{m}$ to exclude fluorescence detection from more than one cell layer. Fluorescence images (excitation at $488 \mathrm{~nm}$, emission at $>505 \mathrm{~nm}$ ) of the olfactory epithelium were acquired in the range of $1.27-2.03 \mathrm{~Hz}$, with 3-10 images taken as control images before the onset of odorant delivery. The fluorescence changes $\Delta F / F$ were calculated for individual ORNs as $\Delta F /$ $F=\left(F_{1}-F_{2}\right) / F_{2}$, where $F_{1}$ was the fluorescence averaged over the pixels of an ORN soma, and $F_{2}$ was the average fluorescence of the same pixels before stimulus application, averaged over five images. A response was assumed if the following two criteria were met: (1) the first two intensity values after stimulus arrival at the mucosa, $\Delta F / F\left(t_{1}\right)$ and $\Delta F / F\left(t_{2}\right)$, had to be larger than the maximum of the prestimulus intensities; and (2) $\Delta F /$
$F\left(t_{2}\right)>\Delta F / F\left(t_{1}\right)$, with $t_{2}>t_{1}$. Data analysis was performed with Matlab (MathWorks).

\section{Patch-clamp recordings}

Tissue slices were visualized using a $40 \times$ water-immersion objective mounted to an Axioscop 2 microscope (Carl Zeiss). Patch electrodes with a tip resistance of 6-10 $\mathrm{M} \Omega$ were fabricated from borosilicate glass with a $1.8 \mathrm{~mm}$ outer diameter (Hilgenberg) by a two-stage pipette puller (PC-10; Narishige) and filled with $4 \mu \mathrm{l}$ of bath solution. ORNs were recorded in the on-cell configuration of the patch-clamp technique after a gigaohm seal was obtained between the patch pipette and the membrane of an individual intact cell. This noninvasive technique makes it possible to record action potential-equivalent charge displacements of the membrane of an individual cell without affecting the composition of its intracellular solution (Hamill et al., 1981). Holding voltage was $0 \mathrm{mV}$. Pulse protocols, data acquisition, and evaluation programs were written in $\mathrm{C}$. The data were digitized online and analyzed with Matlab. Raw data were filtered (Gaussian filters, $\varsigma_{1}=2-5$ and $\varsigma_{2}=100$ ), and their difference was calculated. Data points smaller than $-2.5 \mathrm{pA}$ were classified as action potentials and illustrated as a bar in the respective figure.

\section{Single-cell RT-PCR}

Tissue slices were visualized using a $40 \times$ water-immersion objective mounted to an Axioscop 2 microscope (Carl Zeiss). Patch pipettes with a tip resistance of $6-10 \mathrm{M} \Omega$ were pulled from borosilicate glass with a 1.8 $\mathrm{mm}$ outer diameter (Hilgenberg) by a two-stage pipette puller (PC-10; Narishige) and filled with $4 \mu$ l of pipette solution. Cells were identified as ORNs and SCs based on their morphology. After the formation of a gigaseal, negative pressure was applied to the pipette, and the whole-cell configuration was established (Hamill et al., 1981). ORNs showed spontaneous spiking activity in the on-cell mode and characteristic voltagegated sodium and potassium currents in whole-cell configuration. Sustentacular cells showed no electrical activity. Cell cytoplasm was harvested with the pipette under visual and resistance control by applying negative pressure to the patch pipette. Cells fulfilling these physiological criteria and whose seals remained intact during harvesting the cytoplasm were used for reverse transcription (RT) with a modified protocol of the SuperScriptTM III First-Strand Synthesis System for RT-PCR (Invitrogen). The content of the pipette was immediately expelled into a tube containing 5 ng of random hexamers, 40 U of Rnasin Plus RNase Inhibitor (Promega), $1 \mathrm{~mm}$ dNTPmix, and DEPC water. The mixture was heated to $65^{\circ} \mathrm{C}$ for $5 \mathrm{~min}$ and cooled on ice for at least $1 \mathrm{~min}$. Next, reverse transcription was performed by adding $1 \times \mathrm{RT}$ buffer, $5 \mathrm{mM} \mathrm{MgCl}_{2}, 10$ mM DTT, 2 U of RNaseOUT, and 10 U of SuperScript III RT and incubating at $25^{\circ} \mathrm{C}(10 \mathrm{~min}), 50^{\circ} \mathrm{C}(50 \mathrm{~min}), 85^{\circ} \mathrm{C}(5 \mathrm{~min})$ and chilled on ice. RNA was degraded by adding $1 \mu \mathrm{l}$ of RNase $\mathrm{H}$ and incubating for $20 \mathrm{~min}$ at $37^{\circ} \mathrm{C}$. The cDNA produced in one single-cell RT was split in four tubes and served as the template for PCR. The reactions were performed according to the manual of the FastStart TaqDNA Polymerase (Roche). In brief, the reaction mix contained $200 \mathrm{~nm}$ specific forward and reverse primers for olfactory marker protein 1 (OMP1) (Rössler et al., 1998) (5'-CTTTCTTAGATGGCGCTGACC-3', 5' -GTGGTTATTTCTCTACACTTGG-3'; product length, $404 \mathrm{bp}$ ), cytokeratin type II (CYTII) (5' CATTGATAAGGTCAGGTTCCTG-3', 5' -CACGGAGTTCAGCTTCATAC-3'; product length, $389 \mathrm{bp})$, DAG lipase $\alpha$ (5'-GTCATGGTGAGTCCGACAGAG-3', 5' -TTTGAGAATTGGCGACAGAAG-3'; product length, $210 \mathrm{bp}$ ), or DAG lipase $\beta$ ( $5^{\prime}$-ATGACCTGGTGTTTCCTGGAG-3', 5'-ACACAATGGCAGAGACCACAC-3'; product length, $186 \mathrm{bp}$ ) (Invitrogen), $200 \mu \mathrm{M}$ dNTPs, $1 \times$ PCR buffer, and $2 \mathrm{U}$ of FastStartTaq DNA Polymerase. The reaction was activated at $95^{\circ} \mathrm{C}$ for 5 min and underwent 40 cycles of a temperature protocol of $30 \mathrm{~s}$ at $95^{\circ} \mathrm{C}$, $30 \mathrm{~s}$ at $58^{\circ} \mathrm{C}$, and $45 \mathrm{~s}$ at $72^{\circ} \mathrm{C}$. After a final extension of $7 \mathrm{~min}$ at $72^{\circ} \mathrm{C}$, the PCR products were run on a $2 \%(\mathrm{w} / \mathrm{v})$ agarose gel containing ethidiumbromide (Sigma). Negative control reactions without SuperScript III RT were also performed and never led to any product formation.

\section{Real-time PCR}

Tadpoles were exposed to three different nutritious states. Two groups of animals were food deprived for $6 \mathrm{~h}$ (group $\mathrm{A}_{6 \mathrm{~h}}$ ) or $12 \mathrm{~h}$ 
A1

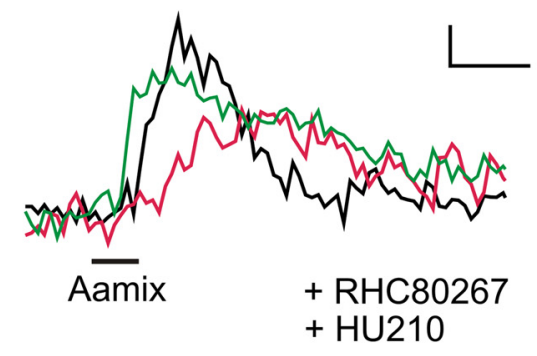

A2
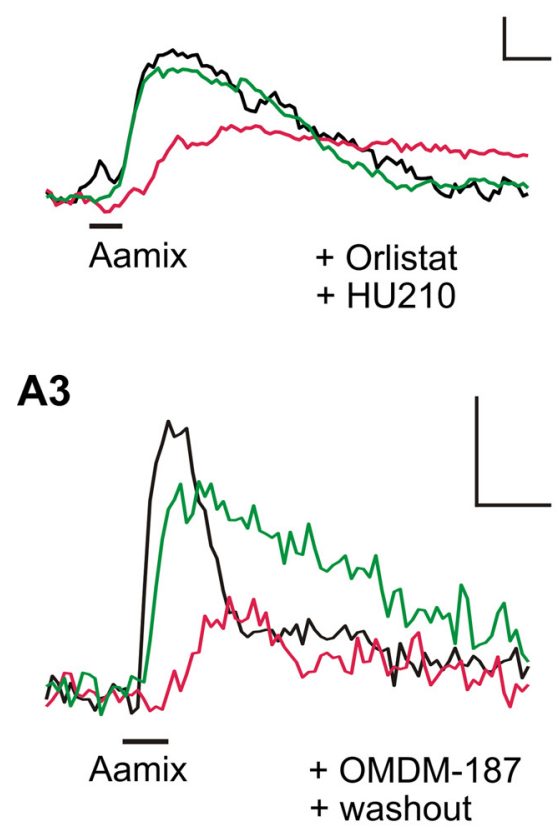

A4

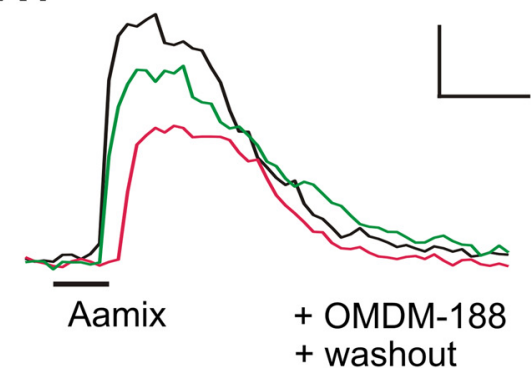

A5

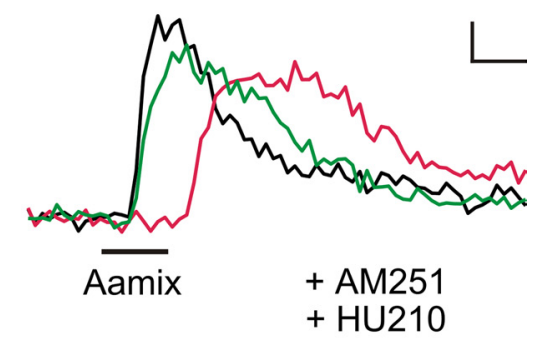

B
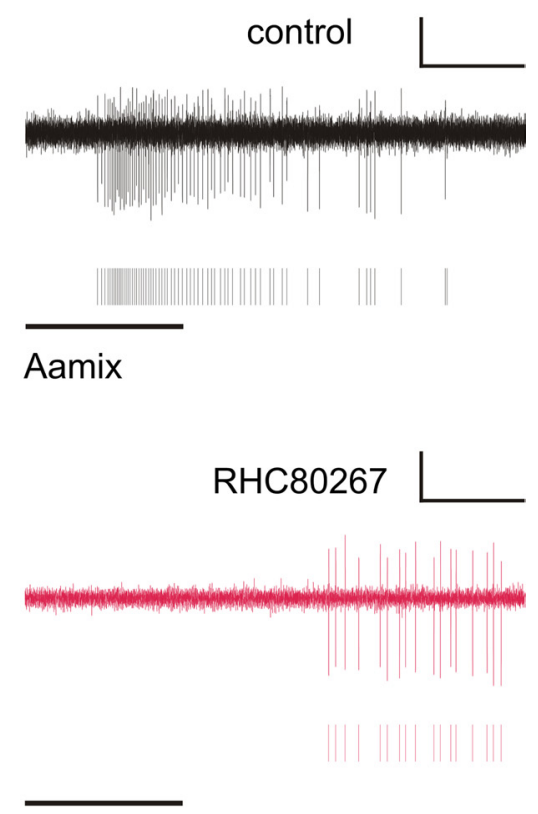

Aamix

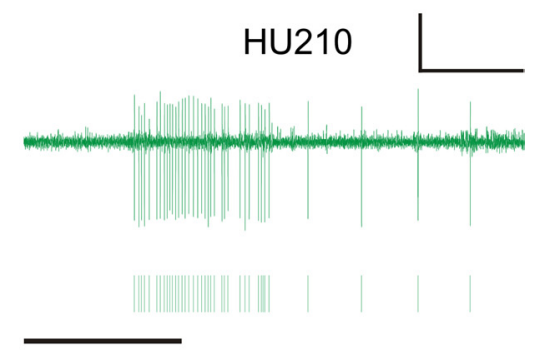

Aamix

Figure 1. Effects of 2-AG synthesis blockage on odorant responses of ORNs. A, Aamix-evoked $\left[\mathrm{Ca}^{2+}\right]_{\mathrm{i}}$ transients in somata of individual ORNs (black traces) were reduced and delayed after wash-in of the DAG lipase inhibitors RHC80267 (50 $\mu \mathrm{m}$; calibration: $10 \mathrm{~s}, \Delta \mathrm{F} / \mathrm{F}$ of $50 \%$ ), orlistat (50 $\mu \mathrm{m}$; calibration: $10 \mathrm{~s}, \Delta \mathrm{F} / \mathrm{F}$ of $25 \%$ ), 0MDM-187 (1 $\mu \mathrm{m}$; calibration: $10 \mathrm{~s}, \Delta F / F$ of $25 \%$ ), and OMDM-188 (100 nm; calibration: $10 \mathrm{~s}, \Delta F / F$ of 50\%), respectively (A1-A4, red traces). This effect was highly reproducible with

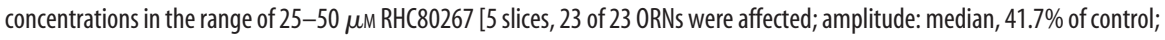
interquartile range (IQR), 36.4\% of control; latency: median, $2.4 \mathrm{~s}$; IQR, 1.3 s), $50 \mu \mathrm{m}$ orlistat (4 slices, 29 of 31 ORNs were affected; amplitude: median, 48\% of control; IQR, 25\% of control; latency: median, 3 s; IQR, 2s), $1 \mu \mathrm{m}$ 0MDM-187 (6 slices, 15 of 56 cells were affected; amplitude: median, $67 \%$ of control; IQR, 26.5\% of control; latency: median, 2 s; IQR, 1 s), or 100 -200 nм 0MDM-188 (5 slices, 50 of 52 ORNs were affected; amplitude: median, $43 \%$ of control; IQR, $22.5 \%$ of control; latency: median, $3 \mathrm{~s} ;$ IQR, $1 \mathrm{~s}$ ). Two minutes after adding HU210 $(10 \mu \mathrm{M})$ to the bath, the $\left[\mathrm{Ca}^{2+}\right]_{\mathrm{i}}$ transients recovered almost completely $(\boldsymbol{A} \mathbf{1}, \boldsymbol{A} \mathbf{2}$, green traces). Twelve of 23 ORNs (5 slices) that were modulated by RHC80267 recovered during HU210 wash-in (amplitude: median, $63.6 \%$ of control; IQR, 27.9\% of control; latency: median, $1.8 \mathrm{~s} ;$ IQR, $2.4 \mathrm{~s}$ ). Seventeen of $17 \mathrm{ORNs}$ ( 2 slices) that were modulated by orlistat recovered during HU210 wash-in (amplitude: median, $57 \%$ of control; IQR, $60 \%$ of control; latency: median, 2s; IQR, 2s). Washout with bath solution also resulted in a recovery of the response after 12 and $8 \mathrm{~min}$, respectively $(\boldsymbol{A} \mathbf{3}, \boldsymbol{A} \mathbf{4}$, green trace; OMDM-187, 7 of 15 ORNs ( 3 slices) recovered; amplitude: median, $73 \%$ of control; IQR, $60 \%$ of control; latency: median, 1 s; IQR, 1.5 s; OMDM-188, 10 of 24 ORNs ( 3 slices) recovered; amplitude: median, $89.5 \%$ of control; IQR, $95.75 \%$ of control; latency: median, 0 s; IQR, $1 \mathrm{~s}$; orlistat, 1 of 12 ORNs ( 2 slices) recovered]. The black lines below the response traces indicate the application of the odorants.

(group $\mathrm{A}_{12 \mathrm{~h}}$ ), and a third group of animals served as a control group and was overfed for $2 \mathrm{~h}(\mathrm{C})$.

RNA isolation and cDNA synthesis. Olfactory epithelia of four animals per condition (each condition was repeated seven times) were cut out of the tissue and stored in liquid nitrogen until RNA isolation. Total RNA was isolated by the TRIzol method (Invitrogen) according to the protocol of the manufacturer, and DNA contaminations were removed by subsequent DNase I treatment (DNase I recombinant, RNase-free; Roche). The RNA quality and quantity was analyzed with the microfluidicsbased electrophoresis system Agilent 2100 Bioanalyzer (Agilent Technologies). Reverse transcription was performed from $1 \mu \mathrm{g}$ of RNA with the iScript cDNA Synthesis kit from Bio$\mathrm{Rad}$ as described in the manual.

$c D N A$ quantification. Quantification of DAG lipase $\alpha$ and $\beta$ mRNA was performed using the iQ SYBR Green Supermix (Bio-Rad) on an iQ5 real-time PCR detection system (Bio-Rad) according to the instructions of the manufacturer. The ATPase $F_{0} F_{1}$ (primer sequences, 5'-GTCAGCGTGAGCTCATCATC-3', 5'-GCATCAGAGGCTGTAGCAGA-3'; product length, $161 \mathrm{bp}$ ) was used as an internal control, and $\mathrm{CB}_{1}$ (primer sequences, 5'-GTGCACACCTCAGAAGATGGA-3', 5' ${ }^{\prime}$ CTGCAGAAGGCAAACACTGTC-3'; product length, 194 $\mathrm{bp}$ ), DAG lipase $\alpha$ (for primer sequences, see above), DAG lipase $\beta$ (for primer sequences, see above), and monoacylglycerol lipase mRNA (primer sequences, 5' -AACACTGCTGCCGATATGATG-3', 5'-GGTCCGGGTATTGTTTCTTCA-3'; product length, $183 \mathrm{bp}$ ) were investigated. The general PCR conditions were as follows: polymerase activation at $98^{\circ} \mathrm{C}$ for $30 \mathrm{~s}$ followed by 40 cycles of denaturation at $94^{\circ} \mathrm{C}$ for $1 \mathrm{~s}$, annealing at $58^{\circ} \mathrm{C}$ for $15 \mathrm{~s}$, and extension at $72^{\circ} \mathrm{C}$ for $1 \mathrm{~s}$. After the amplification, a melt curve analysis verified the formation of the single desired PCR product. The relative gene expression ratios (Kubista et al., 2006) were determined and normalized for control conditions. SEs of the mean intervals were calculated by determining the SD of the logarithmized ratios followed by exposing the left and right borders.

Liquid chromatography-mass spectrometry 2-AG levels in olfactory epithelia of animals at the nutritional statuses mentioned above were measured. For one sample, the olfactory epithelia of 10 animals $(\sim 5 \mathrm{mg})$ were cut out and stored

$\leftarrow$

A5, Addition of the $\mathrm{CB}_{1}$ receptor antagonist $\mathrm{AM} 281(5 \mu \mathrm{M})$ to the bath solution elicited almost identical effects as the DAG lipase blockage (calibration: $10 \mathrm{~s}, \Delta F / F$ of $50 \%$ ). B, Application of Aamix induced action potential-associated currents in an individual ORN (black trace; calibration: $2 \mathrm{~s}, 5 \mathrm{pA}$ ). The DAG lipase blocker RHC80267 (25 $\mu \mathrm{m}$, red trace; calibration: $2 \mathrm{~s}, 5$ $\mathrm{pA}$ ) delayed the odor-evoked firing activity and reduced its frequency. The response recovered after $1 \mathrm{~min}$ of wash-in of HU210 (20 $\mu \mathrm{m}$, green trace; calibration: $2 \mathrm{~s}, 10 \mathrm{pA}$ ). The bars below the current traces illustrate action potentials. 
at $-80^{\circ} \mathrm{C}$. Tissues were extracted in organic solvents, lipid extracts were prepurified and analyzed on silica minicolumns, and endocannabinoids were quantified by isotopic dilution atmospheric pressure-liquid chromatographymass spectrometry as described previously (Marsicano et al., 2002).

\section{Results}

Suppression of 2-AG

production reduces and delays odorant-induced responses

Endocannabinoids play a physiological role in the olfactory epithelium. When the $\mathrm{CB}_{1}$ receptors of ORNs are blocked, responses to odorants are diminished and delayed (Czesnik et al., 2007). This effect could be explained by assuming a tonic synthesis and action of endocannabinoids in the olfactory epithelium. We checked this assumption by blocking 2-AG synthesis using the DAG lipase blockers RHC80267, orlistat, OMDM-187, and OMDM-188. The superfusion with these drugs had two effects. They prolonged the delay and reduced the amplitude of responses of individual ORNs to odorants. The black traces in Figure 1A1-A4 show typical $\left[\mathrm{Ca}^{2+}\right]_{\mathrm{i}}$ responses during application of a mixture of amino acids $(100 \mu \mathrm{M})$ in four different ORNs taken from four different olfactory epithelium slice preparations. Superfusion of the slices with RHC80267 (50 $\mu \mathrm{M}, 12 \mathrm{~min}$ ), orlistat (50 $\mu \mathrm{M}, 10 \mathrm{~min}$ ), OMDM-187 (1 $\mu \mathrm{M}, 20 \mathrm{~min})$, or OMDM188 (100 nM, $16 \mathrm{~min}$ ) diminished and delayed the $\left[\mathrm{Ca}^{2+}\right]_{\mathrm{i}}$ responses (Fig. $1 A 1-A 4$, respectively, red traces). This effect was highly reproducible with concentrations in the range of 25-50 $\mu \mathrm{M}$ RHC80267 (five slices, 23 of 23 ORNs were affected), $50 \mu \mathrm{M}$ orlistat (four slices, 29 of 31 ORNs were affected), $1 \mu \mathrm{M}$ OMDM-187 (six slices, 15 of 56 cells were affected), or 100-200 nM OMDM-188 (five slices, 50 of 52 ORNs were affected).

The responses recovered during washout with bath solution or wash-in of the $\mathrm{CB}_{1}$ receptor agonist HU210 (Fig. 1A1-A4, green traces). Wash-in of HU210 (10 $\mu \mathrm{M})$ led to an almost complete recovery of the responses (Fig. 1A1,A2). Twelve of 23 ORNs (five slices) that were modulated by RHC80267 recovered during HU210 wash-in. Seventeen of 17 ORNs (two slices) that were modulated by orlistat recovered during HU210 wash-in. A washout with bath solution also led to a recovery of the responses (Fig. $1 A 3, A 4)$ (OMDM-187, three slices, 7 of 15 ORNs recovered; OMDM-188, three slices, 10 of 24 ORNs recovered; orlistat, two slices, 1 of 12 ORNs recovered).

The described effects are very similar to those induced by blockage of $\mathrm{CB}_{1}$ receptors as published previously (Czesnik et al., 2007) (Fig. 1A5).

The observed odorant-induced $\left[\mathrm{Ca}^{2+}\right]_{\mathrm{i}}$ changes in ORNs allow only indirect conclusions regarding the information conveyed to the olfactory bulb. Therefore, we tested the effect of the DAG lipase blocker RHC80267 on odor-induced spiking activity by recording spike-associated currents of individual ORNs. Figure $1 B$ shows a typical odor response of an individual ORN mea- sured in the on-cell patch-clamp configuration (black trace). Wash-in of RHC80267 (25 $\mu \mathrm{M})$ increased the delay of the onset of odor-induced spike-associated currents and the interspike interval of the responses (Fig. $1 \mathrm{~B}$, red trace). Similar results were obtained in seven other ORNs (eight ORNs of eight slices). Washout with HU210 $(20 \mu \mathrm{M})$ induced a recovery after $1 \mathrm{~min}$ (green trace).

\section{Differential expression of the DAG lipase isoforms within the olfactory epithelium}

Although the above data demonstrate that the suppression of odorant responses was brought about by the endocannabinoid 2-AG, produced by a DAG lipase, the production site of 2-AG, i.e., the site of DAG lipase activity remained unclear so far. Therefore, we localized the expression of the DAG lipase in the olfactory epithelium, specifically the expression of the $\alpha$ and $\beta$ isoforms. Olfactory receptor neurons and sustentacular cells, which could easily be distinguished on the basis of their characteristic morphology, were first patch clamped and physiologically identified. Then the cytoplasm of the patch-clamped cell was harvested into the patch pipette for additional PCR analysis. The mRNA of OMP1 and CYTII were used as markers to confirm the identity of ORNs and SCs, respectively (Hassenklöver et al., 2008). Five of 10 ORNs (OMP1-positive) expressed DAG lipase $\beta$, and none of them expressed DAG lipase $\alpha$. Conversely, five of eight SCs (CYTII-positive) expressed DAG lipase $\alpha$, and none of them expressed DAG lipase $\beta$. In summary, $2-A G$ is synthesized in both ORNs and SCs, although by two different isoforms of the 
A

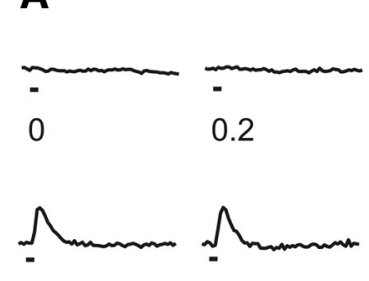

$10 \quad 20$

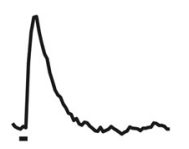

200

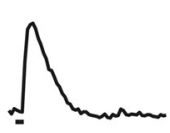

500

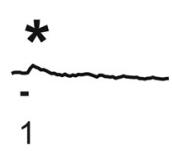

1

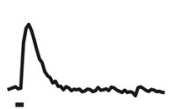

50

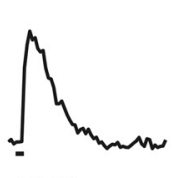

1000

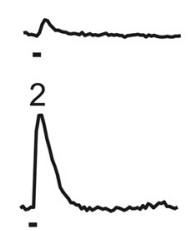

100

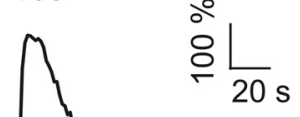

2000 lys
B
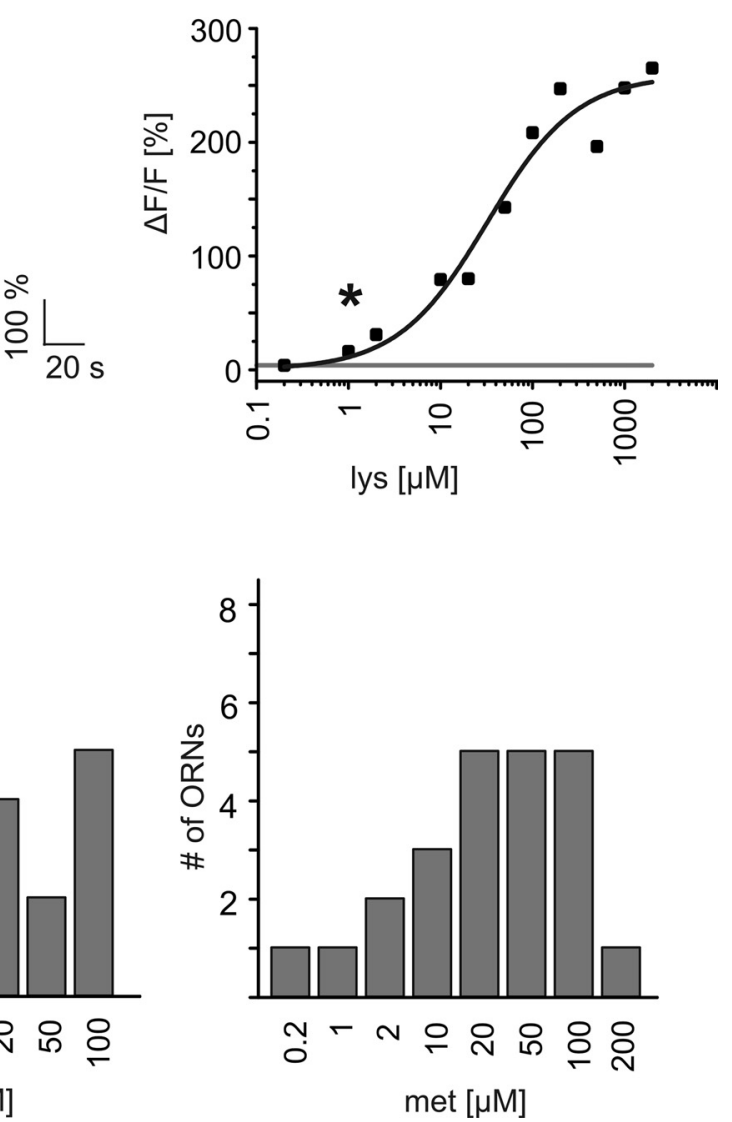

Figure 3. Dose-response relationships of $\left[\mathrm{Ca}^{2+}\right]_{i}$ transients induced by single amino acids. $\boldsymbol{A},\left[\mathrm{Ca}^{2+}\right]_{\mathrm{i}}$ transients of a single 0 RN elicited by increasing concentrations $(0,0.2,1,2,10,20,50,100$, $200,500,1000$, and $2000 \mu \mathrm{m}$ ) of lysine (lys) are shown. The detection threshold concentration ( ${ }^{*}$ ) in this example is $1 \mu \mathrm{m}$. $\boldsymbol{B}$, The dose-response relationship measured (squares) was fitted by the equation $y=A /\left(1+\left(x / x_{0}\right)^{p}\right)$, using ORIGIN 7 (OriginLab Corporation). The gray line (in the plot) indicates the mean level of the subthreshold responses of this ORN. $C$, Detection threshold histograms of all ORNs recorded using lysine (lys), arginine (arg), or methionine (met).

DAG lipase (see examples in Fig. $2 A$ ). The $\beta$ isoform is active in ORNs and the $\alpha$ isoform in SCs.

\section{2-AG levels and the DAG lipase $\alpha$ expression are enhanced after food deprivation}

To find a functional link between the nutritional or hunger state of an animal on the one hand and 2-AG synthesis on the other, we investigated whether hunger affected the concentration of 2-AG in the olfactory epithelium. To this end, olfactory epithelia were cut out and analyzed from three groups of animals. The first and second group of animals were food deprived for either $6 \mathrm{~h}$ (group $\mathrm{A}_{6 \mathrm{~h}}$ ) or $12 \mathrm{~h}$ (group $\mathrm{A}_{12 \mathrm{~h}}$ ) before analyzing their 2-AG levels. A control group of animals (group C) was fed to satiety for $2 \mathrm{~h}$ before measurements (see Materials and Methods). The concentration of 2-AG increased significantly after animals were food deprived for $6 \mathrm{~h}$ or $12 \mathrm{~h}$ compared with the control condition (Fig. 2 B). Specifically, olfactory epithelia of animals that were fed for $2 \mathrm{~h}$ contained $4.9 \pm 0.3 \mathrm{pmol} 2-\mathrm{AG} / \mathrm{mg}$ tissue. Food deprivation elevated the $2-\mathrm{AG}$ concentration in olfactory epithelium to $7.4 \pm 0.4 \mathrm{pmol} / \mathrm{mg}$ tissue $\left(\mathrm{A}_{6 \mathrm{~h}}, n=4\right)$ and $7.5 \pm 0.2 \mathrm{pmol} / \mathrm{mg}$ tissue $\left(\mathrm{A}_{12} \mathrm{~h}, n=4\right)$.

As presented above, we identified the DAG lipases $\alpha$ and $\beta$ in SCs and ORNs, respectively. Thus, we were able to determine the enzyme and the cell type responsible for the enhanced 2-AG levels using real-time PCR. The expression level of both DAG lipase isoforms were obtained and analyzed from three groups of ani- mals exposed to the conditions above. mRNA expression levels for groups $\mathrm{A}_{6 \mathrm{~h}}$ and $\mathrm{A}_{12 \mathrm{~h}}$ were normalized to those of the control group (Fig. 2C, gray line).

Comparing the expression levels of DAG lipase $\alpha$ (blue; SCs) and DAG lipase $\beta$ (red; ORNs), hunger clearly had no effect on 2-AG production in ORNs (Fig. $2 C$, red points), because the normalized changes of the DAG lipase $\beta$ (ORNs) by hunger (groups $\mathrm{A}_{6 \mathrm{~h}}$ and $\mathrm{A}_{12 \mathrm{~h}}$ ) were 0.99 and 0.97 , respectively $(n=7)$ ). In contrast, in SCs, the DAG lipase $\alpha$ was significantly enhanced after food deprivation for both $6 \mathrm{~h}$ (group $\mathrm{A}_{6 \mathrm{~h}}$ ) or $12 \mathrm{~h}$ (group $\left.\mathrm{A}_{12 \mathrm{~h}}\right)$. On average, the mRNA expression levels were 1.45 times $\left(n=7, \mathrm{~A}_{6 \mathrm{~h}}\right)$ or 1.50 times $\left(n=7\right.$, group $\left.\mathrm{A}_{12 \mathrm{~h}}\right)$ higher than in the control group.

The mRNA of both the degrading enzyme of 2-AG, i.e., the monoacylglycerol lipase (MAG lipase), and the $\mathrm{CB}_{1}$ receptor were neither downregulated nor upregulated significantly after food deprivation for both either $6 \mathrm{~h}$ [Fig. 2C, MAG lipase, green points, $\mathrm{A}_{6 \mathrm{~h}}$ (0.76 times, $\left.n=7\right)$; $\mathrm{CB}_{1}$ receptor, orange points, group $\mathrm{A}_{6 \mathrm{~h}}(0.77$ times, $\left.n=7)\right]$ or $12 \mathrm{~h}$ [MAG lipase, green points, group $\mathrm{A}_{12} \mathrm{~h}$ (0.84 times, $\left.n=7\right)$; $\mathrm{CB}_{1}$ receptor, orange points, group $\mathrm{A}_{12 \mathrm{~h}}$ (1.15 times, $\left.n=7\right)$ ].

\section{Sensitivity and response threshold in ORNs}

The above data suggested that 2-AG modulates the sensitivity of ORNs. As to possible sensitivity measures, the obvious candidates were the concentration at which the dose-response curve is half- 
maximum, $K_{1 / 2}$, or the threshold concentration below which an ORN shows no response to the stimulus, $c_{\mathrm{th}}$. We measured dose-response curves of ORNs for a number of stimuli (arginine, methionine, and lysine). Figure $3, A$ and $B$, shows ORN responses to lysine together with the corresponding dose-response curve as an example. We found that the midpoint slopes of the 65 dose-response curves measured varied considerably (by a factor $>10$ ) so that curves having the same $K_{1 / 2}$ had quite different $c_{\text {th }}$ values (data not shown). We therefore preferred to use the threshold concentration, $c_{\text {th }}$, as a convenient measure of sensitivity, whereby $c_{\mathrm{th}}$ is defined as the concentration below which, under control conditions, no responses could be measured. Specifically, we took the first data point of the monotonic increase of the dose-response curve as the detection threshold $c_{\mathrm{th}}$. Note that this definition refers to control conditions (i.e., no food shortage and no drugs applied). The detection thresholds varied from ORN to ORN over a wide range. Figure $3 C$ gives the threshold distributions for the three odorants used.

\section{2-AG controls odorant detection thresholds}

To investigate the effect of 2-AG on the odorant detection threshold of a specific ORN, we first performed a control experiment as shown in Figure $4 \mathrm{~A}$. The orange trace gives an arginine-induced $\left[\mathrm{Ca}^{2+}\right]_{i}$ transient at the detection threshold $c_{\text {th }}$ (in this case, $20 \mu \mathrm{M})$. Expectedly, a higher odorant concentration induced a larger response amplitude and a shorter response latency (black trace), whereas concentrations below $c_{\text {th }}$ failed to elicit a response in this ORN (blue trace). Importantly, this response behavior was well reproducible (Fig. $4 B$, orange and brown traces, blue and light blue traces). Next we superfused the slice with the DAG lipase blocker RHC80267, which consistently led to response failures at $c_{\text {th }}$ (Fig. $4 C$, red trace, RHC80267, $50 \mu \mathrm{M}$ ), meaning that the threshold, $\hat{c}_{\mathrm{th}}$, under the experimental condition of less 2-AG being produced was shifted to a higher value, i.e., $\hat{c}_{\mathrm{th}}>c_{\mathrm{th}}$. Mimicking the presence of 2-AG by wash-in of the $\mathrm{CB}_{1}$ receptor agonist HU210 $(10 \mu \mathrm{M})$ was able to rescue the odorant responses at $c_{\text {th }}$ (Fig. $4 C$, green trace). Moreover, HU210 was not only able to rescue the response; frequently, it also lowered the threshold so that responses could be recorded at subthreshold odorant concentrations $\left(c<c_{\mathrm{th}}\right)$. This

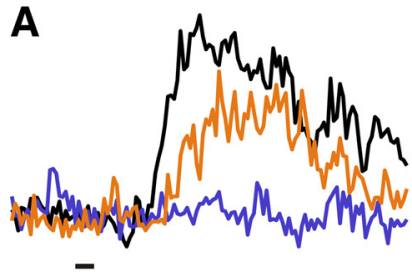

$\arg 50,20,10 \mu \mathrm{M}$

C

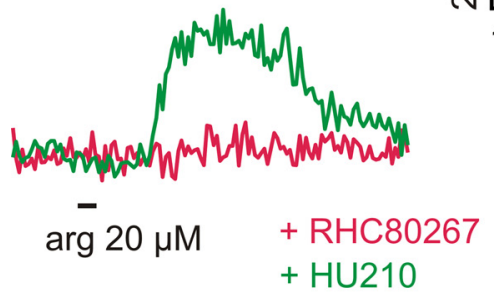

B

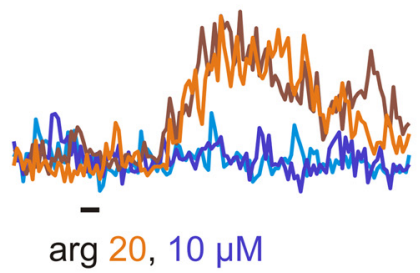

D

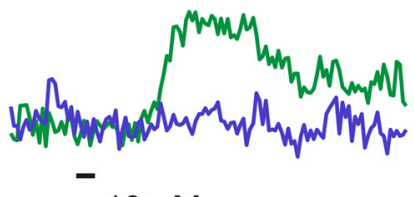

E

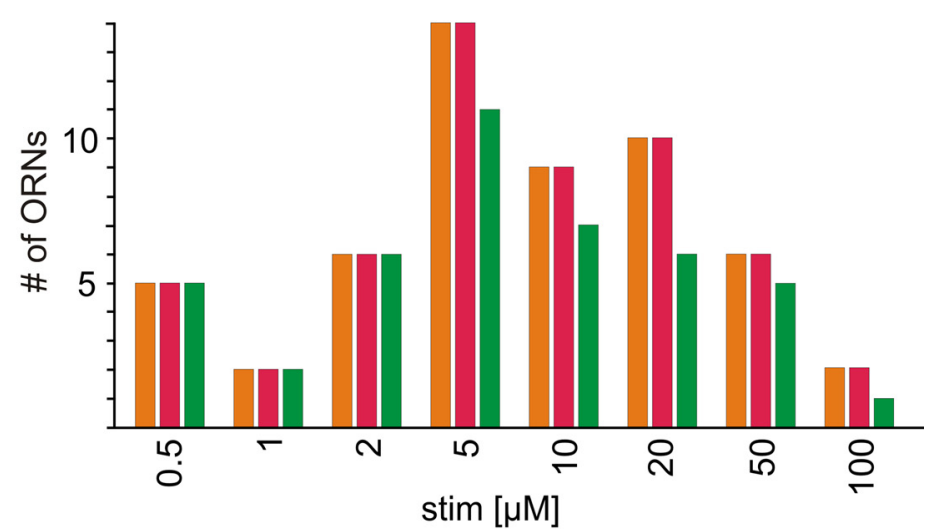

$\mathbf{F}$

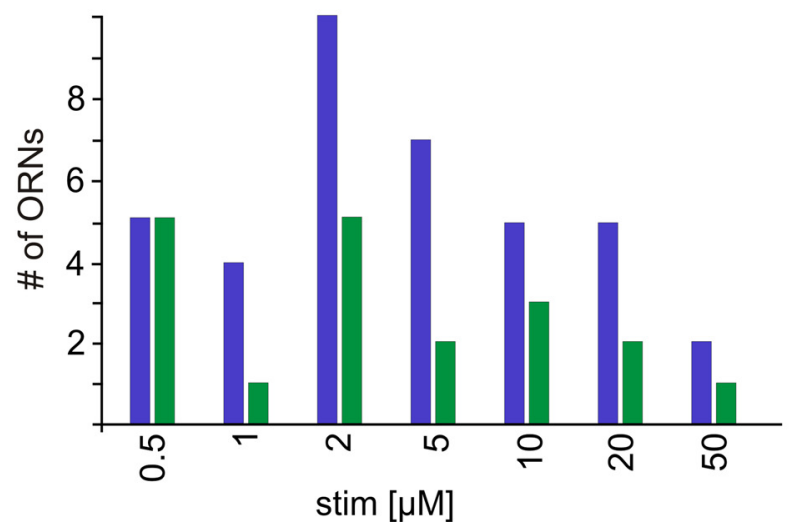

Figure 4. ORNs have individual and tunable odorant detection thresholds depending on the 2-AG level in the olfactory epithelium. $A, 0 R N\left[\mathrm{Ca}^{2+}\right]_{\mathrm{i}}$ responses to various concentrations of arginine $(\arg ; 10,20$, and $50 \mu \mathrm{M}) . \boldsymbol{B}$, The responses at the detection threshold $c_{\mathrm{th}}\left(20 \mu \mathrm{m}\right.$, orange and brown traces) and concentrations below $c_{\mathrm{th}}(10 \mu \mathrm{m}$, blue and light blue traces) were highly reproducible. $C$, After addition of $\mathrm{RH}\left(80267(50 \mu \mathrm{m})\right.$ to the bath solution, the $\left[\mathrm{Ca}^{2+}\right]_{\mathrm{i}}$ transients induced at $c_{\text {th }}$ were abolished (red trace). Recovery of odor responses during the washout of RHC80267 was accelerated with HU210 in the bath solution (2 min, 10 $\mu \mathrm{M}$, green trace) accelerated recovery. D, Lacking odorant response under control conditions (arg, blue trace) and reappearing of odorant response after addition of HU210 ( $2 \mathrm{~min}$, green trace) to the bath. $\boldsymbol{E}$, Threshold histogram of ORNs responsive to arginine, lysine, or methionine under control conditions (orange bars). In all of these ORNs, RHC80267 or orlistat led to a reduction of the response (red bars) whereby a recovery (drug wash-in of HU210 $10 \mu \mathrm{m}$, green bars) could be observed in 42 of 53 ORNs. $\boldsymbol{F}$, Histogram of groups of arginine-, lysine--, or methionine-responsive ORNs (blue bars) plotted over the highest concentration at which no response could be recorded. In 19 of 38 ORNs, HU210 (10 $\mu \mathrm{M})$ permitted responses at the respective concentrations (green bars). 

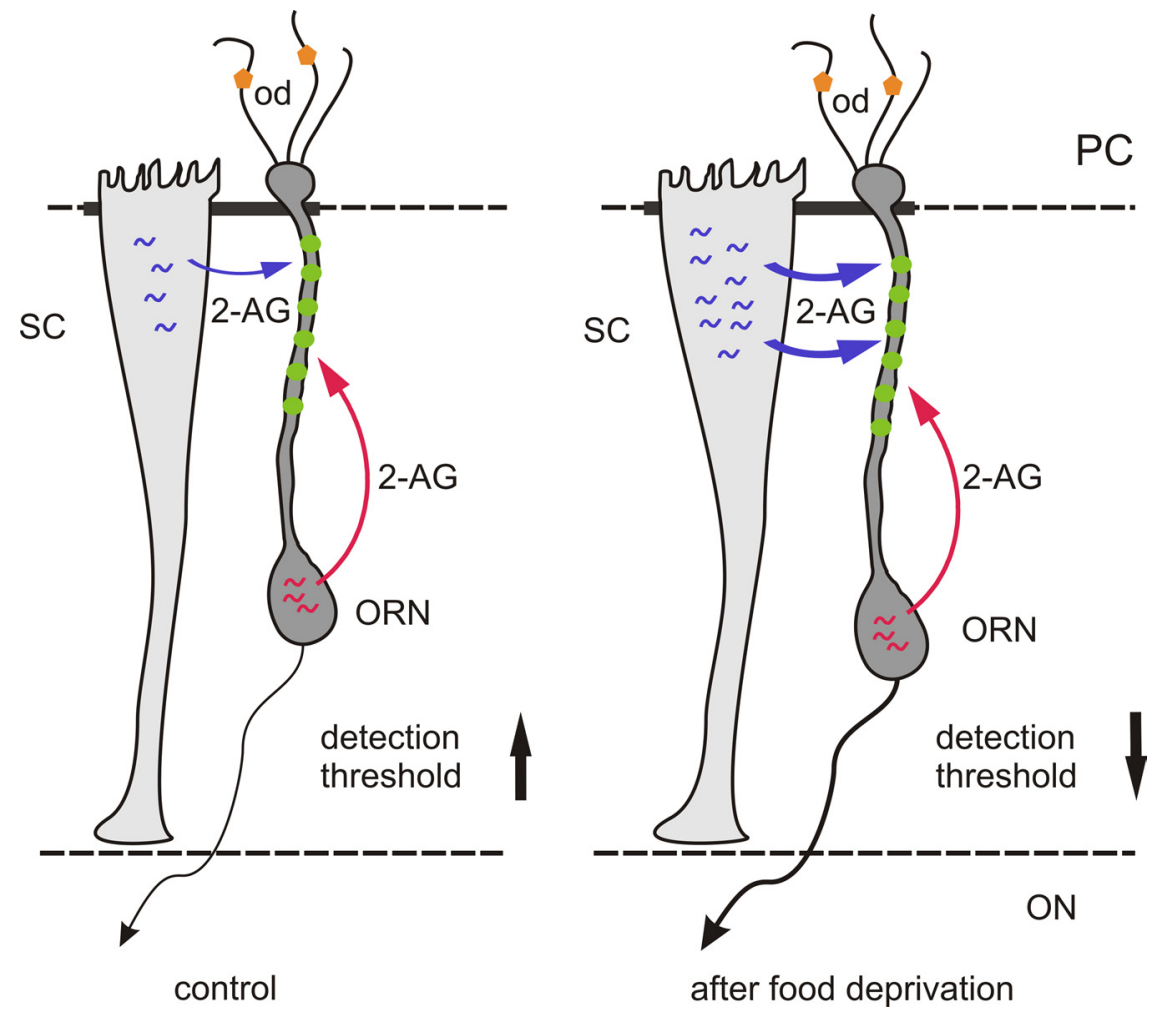

Figure 5. Scheme of paracrine and autocrine actions in the olfactory epithelium. Under control conditions, a tonic level of 2-AG is synthesized. DAG lipase $\alpha$ mRNA synthesis in sustentacular cells ( $\sim$, blue) is enhanced during food deprivation and leads to an enhanced level of 2-AG binding to $C B_{1}$ receptors (green spots) on $0 R N$ dendrites (blue arrows). This renders $0 R N$ s more sensitive. DAG lipase $\beta$ mRNA expression in ORNs ( , red) is not affected during food deprivation. 2-AG synthesized in 0RNs feeds back on ORNs (red arrow). PC, Principal cavity; ON, olfactory nerve; od, odorant.

is shown in Figure $4 D$, in which an odor response failure at $10 \mu \mathrm{M}$ $\left(c<c_{\text {th }}\right.$, blue trace) is transformed into a clear response at the same concentration after HU210 was added to the bath (Fig. $4 D$, green trace). There is thus no doubt that the sensitivities of ORNs are modulated by the endocannabinoid system.

Whereas Figure $4 C$ gave a typical example, Figure $4 E$ summarizes the data for all ORNs recorded under this condition. The cells are grouped with respect to their threshold concentration $c_{\text {th }}$ (abscissa). The left (orange) column of each column triplet of the histogram gives the number of ORNs found to have the threshold concentration indicated on the abscissa. The middle column (red) gives the number of ORNs that show a response suppression (threshold increase) during DAG lipase blockage, and the right column of each column triplet (green) shows how many ORNs regained an odor response after adding HU210 to the bath. An increase of threshold concentration during application of RHC80267 or orlistat was observed in 54 of 54 ORNs (52 slices; 18 cells for arginine, 21 cells for lysine, and 15 cells for methionine; red bars), and the agonist HU210 led to a recovery in 42 of these 54 ORNs (green bar).

Figure $4 F$ summarizes our experiments in which we stimulated at subthreshold concentrations, i.e., at $c<c_{\text {th }}$, at which no responses could be elicited and repeated the stimulation with the $\mathrm{CB}_{1}$ agonist HU210 added to the bath. With HU210 in the bath, responses were observed in 19 (green) of 38 (blue) cells (38 slices). There was no correlation between the occurrence of this effect and the corresponding threshold concentration.

\section{Discussion}

The endocannabinoid system is known to play a crucial role in food intake and energy homeostasis (Matias and Di Marzo,
2007). For instance, in the teleost fish Carassius auratus (Valenti et al., 2005), in the zebra finch (Soderstrom et al., 2004) and in rodents (Di Marzo et al., 2001; Kirkham et al., 2002), brain endocannabinoids seem to act as orexigenic mediators. In addition, the $\mathrm{CB}_{1}$ receptor antagonist AM251 [ $N$-(piperidin-1-yl)-5-(4-iodophenyl)-1-(2,4-dichlorophenyl)-4-methyl-1 $H$-pyrazole-3-carboxamide] induces suppression of food intake and food-reinforced behavior in rats (McLaughlin et al., 2003). The link between exocannabinoids and increased food intake is well known (Hart et al., 2002; Verty et al., 2005). A previous study of ours has shown that the first functional link between cannabinoid action and food intake already resides in the olfactory epithelium (Czesnik et al., 2007), in which the $\mathrm{CB}_{1}$ receptor antagonists AM281, AM251, and LY320135 (4-[6-methoxy2-(4-methoxyphenyl)-1- benzofuran-3carbonyl]benzonitrile) were shown to diminish and delay food odor responses. In that study, however, several important questions remained unanswered. For instance, are endocannabinoids produced in the olfactory epithelium, and if so, where? Is the effect of the $\mathrm{CB}_{1}$ antagonists on ORNs mediated through an autocrine or a paracrine pathway or through both? How do endocannabinoids modulate odor responses, and, finally, is their production modulated by exogenous signals? In the present paper, we tried to answer these questions.

To identify 2-AG as an endocannabinoid acting in the olfactory epithelium, we first investigated the effect induced by the block of 2-AG synthesis. 2-AG is primarily synthesized by the DAG lipases $\alpha$ and $\beta$ (Bisogno et al., 2003; Di Marzo et al., 2005). We showed that the suppression of 2-AG synthesis by the DAG lipase blockers orlistat, RHC80267, OMDM-187, and OMDM188 decreased and delayed the odorant-induced responses. The same effects were obtained with the $\mathrm{CB}_{1}$ receptor antagonists AM281, AM251, and LY320135 applied to the slice (Czesnik et al., 2007).

By single-cell PCR analysis, we detected mRNA of both the DAG lipase $\alpha$ and $\beta$ isoform in SCs and ORNs, respectively. In ORNs, there appears to be an autocrine pathway because 2-AG is produced by DAG lipase $\beta$ in these neurons (Fig. $2 A$, left), and it acts on $\mathrm{CB}_{1}$ receptors on the same cells (Czesnik et al., 2007). In contrast, DAG lipase $\alpha$ mRNA is solely expressed in SCs, indicating an additional paracrine route of $2-\mathrm{AG}$ action in the olfactory epithelium (Fig. $2 \mathrm{~A}$, right). Sustentacular cells are thought to have glia-like characteristics and insulate ORNs (Breipohl et al., 1974) in addition to regulating ion homeostasis in the extracellular space (Farbman, 1992; Morrison and Moran, 1995). Our findings emphasize a novel role of SCs. 2-AG secreted by SCs modulates the activity of ORNs. In other species, orexin and leptin receptors have been shown to be expressed on SCs (Caillol et al., 2003; Getchell et al., 2006). Thus, SCs may receive hormonal input about the hunger state of an animal and control the sensitivity of ORNs by hunger-induced release of endocannabi- 
noids. In agreement with this hypothesis, we found here that the expression of the 2-AG synthesis enzyme DAG lipase $\alpha$ in SCs was increased, causing enhanced levels of 2-AG in the olfactory epithelium after food deprivation. Several studies have indeed been published dealing with the influence of the nutritious state on the neurophysiology of olfactory information processing, whereby an altered sensitivity of ORNs could indirectly be attributed to the effects of modulators such as neuropeptide Y, leptin, or orexin (Caillol et al., 2003; Getchell et al., 2006; Mousley et al., 2006). In the present study, we investigated detection thresholds to arginine, lysine, and methionine. We described their doseresponse relationships and detection thresholds at cellular resolution by using confocal fluo-4 calcium imaging (Manzini et al., 2002; Manzini and Schild, 2003b). Our findings show that response thresholds are distributed over a distinct concentration range between 0.2 and $200 \mu \mathrm{M}$ (Figs. 3, 4), which has also been described by Duchamp-Viret et al. (2000) for ORNs in rat and adult frog. The classical view is that odorant detection thresholds are determined by the affinity and expression level of olfactory receptors (Malnic et al., 1999; Kajiya et al., 2001; Saito et al., 2009), olfactory receptor dimerization (Neuhaus et al., 2004), as well as amplification and adaptation in the transduction cascade (Takeuchi and Kurahashi, 2008). We now show the significant contribution of the endocannabinoid 2-AG to the control of odorant thresholds. Because hunger modulates 2-AG levels in the olfactory epithelium, there appears to be a direct endocannabinoid system-mediated crosstalk between odor coding and the nutritious state of an animal.

As to the autocrine pathway, we did not find any particular modulation of DAG lipases in ORNs, but nevertheless the odorinduced increase of $\left[\mathrm{Ca}^{2+}\right]_{\mathrm{i}}$ might cause 2-AG release [as reported in other neurons (Szabo et al., 2006; Hashimotodani et al., 2007)]. $\left[\mathrm{Ca}^{2+}\right]_{\mathrm{i}}$ transients during odorant stimulation would thus induce, via 2-AG release, a subsequent increase of sensitivity and signal-to-noise ratio. In the future, selective blockers will allow to study the differential effects of the two lipases involved.

Together, our findings support the view that 2-AG acts as an orexigenic modulator in the olfactory epithelium by increasing and decreasing the sensitivity of ORNs to odorants during phases of hunger or satiety (Fig. 5). This would facilitate food seeking, because hungry animals would be able to detect food at concentrations that are not recognized by animals fed to satiety. Modulating the overall odor sensitivity may fasten the recognition of food; however, it would not allow to detect lower concentrations of food. As a consequence, the threshold under control conditions, $c_{\text {th }}$, as we have used it herein, may serve as a simple and convenient definition, but it should only be used if the nutritious conditions are sufficiently well defined.

\section{References}

Aimé P, Duchamp-Viret P, Chaput MA, Savigner A, Mahfouz M, Julliard AK (2007) Fasting increases and satiation decreases olfactory detection for a neutral odors in rats. Behav Brain Res 179:258-264.

Apelbaum AF, Perrut A, Chaput M (2005) Orexin A effects on the olfactory bulb spontaneous activity and odor responsiveness in freely breathing rats. Regul Pept 129:49-61.

Bisogno T, Howell F, Williams G, Minassi A, Cascio MG, Ligresti A, Matias I, Schiano-Moriello A, Paul P, Williams EJ, Gangadharan U, Hobbs C, Di Marzo V, Doherty P (2003) Cloning of the first sn1-DAG lipases points to the spatial and temporal regulation of endocannabinoid signaling in the brain. J Cell Biol 163:463-468.

Breipohl W, Laugwitz HJ, Bornfeld N (1974) Topological relations between the dendrites of olfactory sensory cells and sustentacular cells in different vertebrates. An ultrastructural study. J Anat 117:89-94.

Caillol M, Aïoun J, Baly C, Persuy MA, Salesse R (2003) Localization of orexins and their receptors in the rat olfactory system: possible modula- tion of olfactory perception by a neuropeptide synthetized centrally or locally. Brain Res 960:48-61.

Czesnik D, Schild D, Kuduz J, Manzini I (2007) Cannabinoid action in the olfactory epithelium. Proc Natl Acad Sci U S A 104:2967-2972.

Di Marzo V, Goparaju SK, Wang L, Liu J, Bátkai S, Járai Z, Fezza F, Miura GI, Palmiter RD, Sugiura T, Kunos G (2001) Leptin-regulated endocannabinoids are involved in maintaining food intake. Nature 410:822-825.

Di Marzo V, De Petrocellis L, Bisogno T (2005) The biosynthesis, fate and pharmacological properties of endocannabinoids. Handb Exp Pharmacol 168:147-185.

Duchamp-Viret P, Duchamp A, Chaput MA (2000) Peripheral odor coding in the rat and frog: quality and intensity specification. J Neurosci 20:2383-2390.

Duclaux R, Feisthauer J, Cabanac M (1973) Effects of a meal on the pleasantness of food and nonfood odorants in man. Physiol Behav 10:1029-1033.

Egertová M, Elphick MR (2000) Localisation of cannabinoid receptors in the rat brain using antibodies to the intracellular C-terminal tail of CB. J Comp Neurol 422:159-171.

Engeli S (2008) Dysregulation of the endocannabinoid system in obesity. J Neuroendocrinol 20 [Suppl 1]:S110-S115.

Farbman AI (1992) The cell biology of olfaction. New York: Cambridge UP. Fedoroff IC, Stoner SA, Andersen AE, Doty RL, Rolls BJ (1995) Olfactory dysfunction in anorexia and bulimia nervosa. Int J Eat Disord 18:71-77.

Getchell TV, Kwong K, Saunders CP, Stromberg AJ, Getchell ML (2006) Leptin regulates olfactory-mediated behavior in ob/ob mice. Physiol Behav 87:848-856.

Hamill OP, Marty A, Neher E, Sakmann B, Sigworth FJ (1981) Improved patch-clamp techniques for high-resolution current recording from cells and cell-free membrane patches. Pflugers Arch 391:85-100.

Hart CL, Ward AS, Haney M, Comer SD, Foltin RW, Fischman WM (2002) Comparison of smoked marijuana and oral Delta(9)-tetrahydrocannabinol in humans. Psychopharmacology (Berl) 164:407-415.

Hashimotodani Y, Ohno-Shosaku T, Kano M (2007) $\mathrm{Ca}^{2+}$-assisted receptor-driven endocannabinoid release: mechanisms that associate presynaptic and postsynaptic activities. Curr Opin Neurobiol $17: 360-365$.

Hassenklöver T, Kurtanska S, Bartoszek I, Junek S, Schild D, Manzini I (2008) Nucleotide-induced $\mathrm{Ca}^{2+}$ signaling in sustentacular supporting cells of the olfactory epithelium. Glia 56:1614-1624.

Horvath TL (2006) The unfolding cannabinoid story on energy homeostasis: central or peripheral site of action? Int J Obes (Lond) 30 [Suppl 1]:S30-S32.

Julliard AK, Chaput MA, Apelbaum A, Aimé P, Mahfouz M, Duchamp-Viret $P$ (2007) Changes in rat olfactory detection performance induced by orexin and leptin mimicking fasting and satiation. Behav Brain Res 183:123-129.

Kajiya K, Inaki K, Tanaka M, Haga T, Kataoka H, Touhara K (2001) Molecular bases of odor discrimination: reconstitution of olfactory receptors that recognize overlapping sets of odorants. J Neurosci 21:6018-6025.

Kirkham TC, Williams CM, Fezza F, Di Marzo V (2002) Endocannabinoid levels in rat limbic forebrain and hypothalamus in relation to fasting, feeding and satiation: stimulation of eating by 2-arachidonoyl glycerol. Br J Pharmacol 136:550-557.

Kopala LC, Good K, Goldner EM, Birmingham CL (1995) Olfactory identification ability in anorexia nervosa. J Psychiatry Neurosci 20:283-286.

Kubista M, Andrade JM, Bengtsson M, Forootan A, Jonák J, Lind K, Sindelka R, Sjöback R, Sjögreen B, Strömbom L, Ståhlberg A, Zoric N (2006) The real-time polymerase chain reaction. Mol Aspects Med 27:95-125.

Mackie K (2005) Distribution of cannabinoid receptors in the central and peripheral nervous system. Handb Exp Pharmacol 168:299-325.

Malnic B, Hirono J, Sato T, Buck LB (1999) Combinatorial receptor codes for odors. Cell 96:713-723.

Manzini I, Schild D (2003a) Multidrug resistance transporters in the olfactory receptor neurons of Xenopus laevis tadpoles. J Physiol 546:375-385.

Manzini I, Schild D (2003b) cAMP-independent olfactory transduction of amino acids in Xenopus laevis tadpoles. J Physiol 551:115-123.

Manzini I, Rössler W, Schild D (2002) cAMP-independent responses of olfactory neurons in Xenopus laevis tadpoles and their projection onto olfactory bulb neurons. J Physiol 545:475-484.

Marsicano G, Wotjak CT, Azad SC, Bisogno T, Rammes G, Cascio MG, Hermann H, Tang J, Hofmann C, Zieglgänsberger W, Di Marzo V, Lutz B 
(2002) The endogenous cannabinoid system controls extinction of aversive memories. Nature 418:530-534.

Matias I, Di Marzo V (2007) Endocannabinoids and the control of energy balance. Trends Endocrinol Metab 18:27-37.

Matias I, Cristino L, Di Marzo V (2008) Endocannabinoids: some like it fat (and sweet too). J Neuroendocrinol 20:100-109.

McLaughlin PJ, Winston K, Swezey L, Wisniecki A, Aberman J, Tardif DJ, Betz AJ, Ishiwari K, Makriyannis A, Salamone JD (2003) The cannabinoid CB1 antagonists SR 141716A and AM 251 suppress food intake and food-reinforced behavior in a variety of tasks in rats. Behav Pharmacol 14:583-588.

McPartland JM, Matias I, Di Marzo V, Glass M (2006) Evolutionary origins of the endocannabinoid system. Gene 370:64-74.

Morrison EE, Moran DT (1995) Anatomy and ultrastructure of the human olfactory neuroepithelium, In: Handbook of olfaction and gustation (Doty RL, ed), pp 75-101. New York: Dekker.

Mousley A, Polese G, Marks NJ, Eisthen HL (2006) Terminal nerve-derived neuropeptide and modulates physiological responses in the olfactory epithelium of hungry axolotls (Ambystoma mexicanum). J Neurosci 26:7707-7717.

Neuhaus EM, Gisselmann G, Zhang W, Dooley R, Störtkuhl K, Hatt H (2005) Odorant receptor heterodimerization in the olfactory system of Drosophila melanogaster. Nat Neurosci 8:15-17.

Nieuwkoop PD, Faber J (1994) Normal table of Xenopus laevis (Daudin). New York: Garland.

Nikonov AA, Finger TE, Caprio J (2005) Beyond the olfactory bulb: an odotopic map in the forebrain. Proc Natl Acad Sci U S A 102:18688-18693.

Ortar G, Bisogno T, Ligresti A, Morera E, Nalli M, Di Marzo V (2008) Tetrahydrolipstatin analogues as modulators of endocannabinoid 2-arachidonoylglycerol metabolism. J Med Chem 51:6970-6979.

Osei-Hyiaman D, Harvey-White J, Bátkai S, Kunos G (2006) The role of the endocannabinoid system in the control of energy homeostasis. Int J Obes (Lond) 30 [Suppl 1]:S33-S38.

Rolls ET (2005) Taste, olfactory, and food texture processing in the brain, and the control of food intake. Physiol Behav 85:45-56.
Rössler P, Mezler M, Breer H (1998) Two olfactory marker proteins in Xenopus laevis. J Comp Neurol 395:273-280.

Saito H, Chi Q, Zhuang H, Matsunami H, Mainland JD (2009) Odor coding by a mammalian receptor repertoire. Sci Signal 2:ra9.

Soderstrom K, Tian Q, Valenti M, Di Marzo V (2004) Endocannabinoids link feeding state and auditory perception-related gene expression. J Neurosci 24:10013-10021.

Sorensen PW, Caprio J (1998) Chemoreception. In: The physiology of fishes (Evans DH, ed), pp 251-261. Boca Raton, FL: CRC.

Szabo B, Urbanski MJ, Bisogno T, Di Marzo V, Mendiguren A, Baer WU, Freiman I (2006) Depolarization-induced retrograde synaptic inhibition in the mouse cerebellar cortex is mediated by 2-arachidonoylglycerol. J Physiol 577:263-280.

Takeuchi H, Kurahashi T (2008) Distribution, amplification, and summation of cyclic nucleotide sensitivities within single olfactory sensory cilia. J Neurosci 28:766-775.

Tsou K, Brown S, Sañudo-Peña MC, Mackie K, Walker JM (1998) Immunohistochemical distribution of cannabinoid $\mathrm{CB} 1$ receptors in the rat central nervous system. Neuroscience 83:393-411.

Valenti M, Cottone E, Martinez R, De Pedro N, Rubio M, Viveros MP, Franzoni MF, Delgado MJ, Di Marzo V (2005) The endocannabinoid system in the brain of Carassius auratus and its possible role in the control of food intake. J Neurochem 95:662-672.

Valentincic T, Lamb CF, Caprio J (1999) Expression of a reflex biting/snapping response to amino acids prior to first exogenous feeding in salmonid alevins. Physiol Behav 67:567-572.

Verty AN, McGregor IS, Mallet PE (2005) Paraventricular hypothalamic $\mathrm{CB}$ (1) cannabinoid receptors are involved in the feeding stimulatory effects of Delta(9)-tetrahydrocannabinol. Neuropharmacology 49:11011109.

Yoshida R, Ohkuri T, Jyotaki M, Yasuo T, Horio N, Yasumatsu K, Sanematsu K, Shigemura N, Yamamoto T, Margolskee RF, Ninomiya Y (2010) Endocannabinoids selectively enhance sweet taste. Proc Natl Acad Sci U S A 107:935-939. 